Revista de la red interuniversitaria de estudios sobre las literaturas rioplatenses contemporáneas en Francia

$8 \mid 2013$

Argentina y Uruguay: lecturas del país vecino en la literatura rioplatense contemporánea (siglos XX y XXI)

\title{
La cayorra sin patente
}

Guido Herzovich

\section{OpenEdition}

Journals

Edición electrónica

URL: http://journals.openedition.org/lirico/1029

DOI: 10.4000/lirico.1029

ISSN: 2262-8339

Editor

Réseau interuniversitaire d'étude des littératures contemporaines du Río de la Plata

Referencia electrónica

Guido Herzovich, «La cayorra sin patente », Cuadernos LIRICO [En línea], 8 | 2013, Publicado el 01 enero 2013, consultado el 22 septiembre 2020. URL : http://journals.openedition.org/lirico/1029 DOI : https://doi.org/10.4000/lirico.1029

Este documento fue generado automáticamente el 22 septiembre 2020

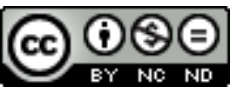

Cuadernos LIRICO está distribuido bajo una Licencia Creative Commons Atribución-NoComercialSinDerivar 4.0 Internacional 


\section{La cayorra sin patente}

Guido Herzovich

\section{REFERENCIA}

Fabián Severo, Noite nu norte $=$ Noche en el norte. Poesía de la frontera, Montevideo, Rumbo Editorial, 2011, $180 \mathrm{p}$. 
En otro tiempo, tal vez la cayorra sin patente hubiera podido aspirar a las páginas del Manual de zoología fantástica de Borges, donde América Latina, generalmente tan prolífica en bestias, aportaba sin embargo únicamente una : la chancha con cadenas, oriunda de la ciudad de Córdoba. Para las autoridades (incluidas las literarias), la cayorra fue seguramente en aquel tiempo tan furtiva como la chancha, aunque sin duda más ubicua. Cuando se la quería avistar, también esta "cayorra" de la frontera uruguayo-brasileña "desaparecía misteriosamente", sin dejar rastros.

2 Vinieron una vez para llevársela, nos cuenta Fabián Severo en el poema

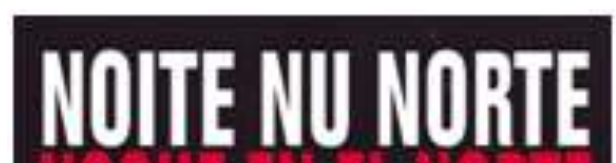

"Vintisinco" :

Yo yoré uma volta que vinieron los de la perrera

i yo tava iscondido con la Chata

imbaiyo da cama de mis padre.

Eyos querían yevarla porque los vesino denunsiaron.

Era serto que la Chata saía ladrando

detrás das bisicleta, das moto i dus auto.

Uma volta

un viejo cayó da mordida que eya deu nel toviyo del.

Mas yo no quería que yevaran eya.

Mi madre dise que na miña casa vasés nou entra

i eles que avía denunsia

i que la cayorra no tiene patente ${ }^{1}$

La Chata, "cayorra sin patente", vive tan al margen de la normativa estatal como el "portuñol" de Artigas, la ciudad uruguaya de la frontera con Brasil en que Fabián Severo escribió sus poemas.

Pero de aquel tiempo a esta parte las cosas cambiaron bastante, aunque menos para los perros que muerden a sus vecinos que para las lenguas que se resisten a la homogeneización estatal. Estigmatizado por la escuela, perseguido en particular durante la dictadura "cívico-militar" (1973-85), el "portuñol" de la frontera uruguaya tiene hoy condiciones sensiblemente mejores para aspirar tanto al reconocimiento que le ha llegado ya por vía del bautismo (DPU : Dialecto Portugués de Uruguay), como a una legítima existencia literaria. Y de eso se trata quizás en Noite nu norte, publicado en 2010, vuelto a publicar en edición bilingüe en 2011, ganador del Premio Morosoli de Bronce, merecedor de una repercusión considerable.

Esa aspiración y esas nuevas condiciones ya estaban indicadas en los paratextos de la primera edición y se mantienen en la segunda. El prólogo de Javier Etchemendi, que firma como "Poeta" y se presenta como montevideano, se ocupa de hacer la ontología de la frontera como espacio de producción, a la vez de esta poesía y de la subjetividad que la enuncia. Si bien Severo la consagra como fórmula recién en la segunda edición ("Poesía de la frontera"), esta inscripción es programática en el texto mismo, que desde 
el comienzo va desgranando su circunstancia en una sucesión de viñetas metafóricas. Su origen es y no es Artigas : lo es en tanto espacio alejado de la "capital", que existe allí apenas como "uma ruta que se perde rumbo ao sur" ("Dois"); no lo es, en cambio, en cuanto espacio dividido por la pertenencia de clase :

Noum sei como será nas terra sivilisada

mas ein Artigas

viven los que tienen apeyido.

Los Se Ninguéim

como eu

semo da frontera

neim daquí neim dalí

("Treis")

6 El tema de la "pertenencia" recorre el libro en tanto parecería, a primera vista, que aquí no se habla de otra cosa que de carencias. ¿De quién es Artigas? "Nu verano / as tarde de Archigas soum das chicharra. / Nu invierno / de ninguém"3 ("Cuatru"). Pero enseguida: "Artigas ta feyado con candado" ("Cincu"); y un momento después : "Archigas no tiene presidente" ("Sete"). La numeración de los poemas, del "Uno" al "Sincuentioito", señala así hasta cierto punto una verdadera progresión, que no impide sin embargo la persistencia de los temas; y aunque encuentran puntos de condensamiento, tienden más bien a la acumulación. La serie de viñetas sobre la condición fronteriza culmina así en una afirmación deíctica, sin nombre propio : "Antes, / eu quiría ser uruguayo. / Agora / quiero ser daquí"4 ("Tresi").

7 En "Nove" entramos explícitamente en el problema de la lengua: "Artigas teim uma lingua sin dueño" ; y en "Des" : "Miña lingua le saca la lengua al disionario". A pesar de que Severo, "con su derecho a llamar a su habla materna como se le antoje" -según dice el epílogo-, elige para su lengua el nombre más "fronterizo" de todos ("Poemas en portuñol" era el subtítulo de la primera edición), en este terreno hay una afirmación muy clara. Artigas podrá ser de los que tienen apellido ; la lengua, en cambio, que nadie quiere ("muchos" la consideran "fea" o "apátrida", informa el epílogo), puede ser terreno fecundo para una afirmación radical. Parte central de esa afirmación es la ficción de un paso a la escritura sin la mediación de ninguna lengua normalizada :

Yo no sabía que pudía iscrevé

asta que mi padriño un día dise

Yiribibe, tu vas fasé istoria.

El no dise con esas palabra

purque el falava mui bien.

Intonse impesé iscrevé ${ }^{5}$.

("Vintitrés")

Las escenas de escritura afirman igualmente para ella este mismo "estatuto". Son escenas privadas, en la mesa de la cocina, con mate y galletitas; se conversa, se ríe y se registran los recuerdos: "Vo iscrevé las lembransa pra no isquesé" ${ }^{6}$ comenzaba el primer poema ("Uno") ; y más adelante : "agora temo casa i tamo isperando ijo. / Yo iscrevo pra amostrar el día que u gurí pergunte"7 ("Vintitrés"). Hay en estas escenas un espíritu evidentemente anti-institucional en su sentido "republicano", en tanto la producción y la circulación de esta escritura parece no vislumbrar ningún horizonte más allá del doméstico. Pero tampoco la institución literaria, con sus mitos y sus demandas, cuyo paroxismo ha correspondido a menudo a la poesía, se animaría seguramente a entrar a la cocina. 
9 Lo que verá el gurí el día en que pregunte es una verdadera etnología de prácticas ligadas a la carencia, moduladas en un tono que, en términos estrictamente literarios, se entrega al más puro miserabilismo. Son las prácticas que anclan en lo social la propiedad de esta lengua "salvaje" : prácticas ligadas a la necesidad física o psicológica, al hambre y a la vergüenza. En tanto escenas de infancia, que la memoria recupera además con histriónica ingenuidad infantil, su efectividad reside en su cualidad prepolítica. Suscitan en el lector, así, una respuesta igualmente teatral, que exige menos articulación simbólica y paso a la acción que reconocimiento y empatía. El primer lector en dejar testimonio de este fenómeno ha sido en efecto "el primer lector", el prologuista :

No conozco la frontera y este libro habla de ella, está construido por ella. Ahora tampoco la conozco pero me duele. $Y$ es un dolor desconocido, imperdonable. Yo estaba cómodamente aquí y ahora... el fuego, la luz, las radios a pila, la lengua de los bichos y el peligro de lo que no se puede definir... un espanto8.

10 Firmado por el "Investigador / Universidad de la República" Luis E. Behares, el epílogo cierra dictaminando la "propiedad" de la lengua. Nos indica que "en sus páginas vibra esa habla deliciosa y verdadera, patrimonio de sus hablantes, los artiguenses, singularizada por su hablante, Fabián Severo". Se trata, nos dice, de "una variedad ágrafa del portugués con mayor o menor influencia del español", distinta de la que se habla en otras ciudades de la misma frontera, inestable por naturaleza y sujeta a una innovación constante. De modo que aquí la carencia (de diccionarios, de reglas, de escritura, de escuela) se vuelve ipso facto propiedad radical : sólo una lengua de estas características pertenece verdaderamente a sus usuarios. En la escritura de esa lengua propia, sin embargo, se ponen en juego otros mecanismos :

Severo no traduce, ni transcribe, translitera. Traducir es adjuntar el sentido en una lengua al sentido en otra, como lo han hecho por ejemplo Bisio y Simões, por lo cual el portugués de Rivera pudo ser dicho en español. Transcribir es lo que hacen los lingüistas, como yo mismo y otros lo hemos hecho en varios momentos con estas hablas fronterizas, o sea buscar las letras más adecuadas para que el que lee identifique el sonido que ésta representa. Transliterar es de otro orden, ciertamente paradojal : se apoya en la letra o en el texto para hacer del habla un otro totalmente otro, pero que sin embargo no puede dejar de responder al mismo que lo origina. Tarea difícil que el verdadero hablante acaba haciendo con su lengua materna sin notarlo, a pesar de la enorme dificultad, y que para el que intenta transliterar una lengua extranjera aunque conocida es una tarea agobiante y angustiante. Es esto último lo que a mi criterio nos entrega Severo aquí, como un disfrutable resultado.

11 La paradoja evidente de la oralidad transliterada de Severo es que aquí la escritura no puede ser ni convencional ni fonética. "No sabemos si pronunciar con inflexión castellana o portuguesa -observó Jens Andermann respecto de Mar paraguayo, novela en portuñol de Wilson Bueno-, encontrándonos literalmente en el espacio de ilegalidad de un habla migrante, exiliados de las leyes y las certezas de la lengua nacional" (14). En Noite nu norte, sin embargo, ese "otro" por el que pasa el trabajo de transliteración queda inscripto precisamente en su voluntad contra-ortográfica. Como ocurría de algún modo con la gauchesca, lengua inculta escrita por señores de la ciudad, Severo, que conoce indudablemente la ortografía estándar del español y el portugués, no puede singularizar su "portuñol" sino a condición de incumplir deliberadamente las dos. "Esta escritura de los recuerdos va en el sentido profundo de la transliteración -propone Behares-, en la medida en que la memoria exige ese 
movimiento en el que 'las lembransa' deben ser escritas para 'no isquesé', alterizarse para permanecer".

Esa circunstancia no impide aquí (como tampoco en la gauchesca) que el libro consiga su objetivo y nos ofrezca ante todo una voz, en el sentido físico de una presencia sonora, por indecidible que nos resulte su pronunciación -a menos que oigamos a Severo leyéndolos en Youtube. Esa voz, verdaderamente hipnótica, se constituye en un continuum de carencias redimidas: el territorio "sin presidente", la lengua "sin diccionario" y la pobreza -se diría, aunque aquí es implícito-sin patrón son redimidas en la memoria de toda su angustia y su ilegitimidad, en una operación de algún modo típica, por la libertad y por los lazos de solidaridad que permite.

La cayorra sin patente pudo ser una monstruosa invención humana, de esas que en los viejos buenos tiempos de la "razón de Estado" hacían estallar en pedazos todo intento de clasificación. Pudo entrar al Manual de Borges o ser objeto de un sofisticado encomio deleuziano, como aquel con el que Perlongher prologó Mar paraguayo. Al releer la novela de Wilson Bueno en 2011, a casi veinte años de su publicación, Jens Andermann propuso ubicarla en el ocaso de la "utopía letrada", indisociable de la modernidad literaria en América Latina : aquella que aspiraba a articular, por medio de una alianza entre literatura y lengua nacional, "el decir popular a la escritura constituyente y ordenadora del Estado" (12).

En efecto, de un tiempo a esta parte ciertas cosas parecen estar cambiando. La frontera como espacio metafórico de una sensibilidad propiamente "contemporánea" ("Todos nos semo da frontera"9 dice el último poema) ha sido ya fetichizada por la bibliografía académica. Las nuevas constituciones de la región se definen como "multiculturales" (Colombia) o incluso "plurinacionales" (Bolivia). La legitimidad literaria del portuñol, en una era en que el expansionismo catalán del Ramón Llul ha vuelto obsoleta la vieja ecuación militarista de los lingüistas ( 1 idioma $=1$ dialecto +1 ejército), tiene todo para encontrar suelo fecundo: pocos días antes de la redacción de esta nota, Paraguay aprobaba la creación de una Academia de Lengua Guaraní. Hora de que la cayorra salga de abajo de la cama y vaya a buscar su patente y su pedigrí.

Si, según Andermann, el portuñol idiosincrático de Wilson Bueno, cruzado además justamente con el guaraní, era corrosión de "la lengua identitaria" y "transgresión lingüística" (16), en Noite nu norte es su exacto opuesto : acto de desagravio, acción afirmativa, política de identidad.

\section{BIBLIOGRAFÍA}

J. Andermann, “Abismos del tercer espacio : Mar paraguayo, portuñol salvaje y el fin de la utopía letrada”. Revista Hispánica Moderna 64 (1), Junio 2011, pp. 11-22.

N. Perlongher, "Sopa paraguaya", en Wilson Bueno, Mar paraguayo, Buenos Aires, Tsé Tsé, 2005. 


\section{NOTAS}

1. "Lloré una vuelta que vinieron los de la perrera / y yo estaba escondido con la Chata / debajo de la cama de mis padres. / Ellos querían llevarla / porque los vecinos habían denunciado. / Era cierto que la Chata salía ladrando / atrás de las bicicletas, las motos y los autos. / Una vuelta / un viejo cayó de la mordida que ella le dio en el tobillo. / Pero yo no quería que la llevaran. / Mi madre les dijo na miña casa vosés noum entra / y ellos que había denuncia / y que la perra no tenía patente" (133-4).

2. "No sé cómo será en las tierras civilizadas / pero en Artigas / viven los que tienen apellido. / Los Juan Nadie / como yo / somos de la frontera. / Ni de aquí ni de allí / no es nuestro el suelo que pisamos / ni la lengua que hablamos" (110).

3. "En verano / las tardes de Artigas son de las chicharras. / En invierno / de nadie" (111).

4. "Antes / yo quería ser uruguayo. / Ahora / quiero ser de acá" (120).

5. "Yo no sabía que podía escribir / hasta que mi padrino, un día dijo / Yiribibe, tu vas fasé istoria. / Él no usó esas palabras / porque él hablaba muy bien. / Entonces empecé a escribir" (130).

6. "Voy a escribir los recuerdos para no olvidar" (108).

7. "Ahora tenemos casa y estamos esperando un hijo. / Escribo para mostrar el día que el niño pregunte" (130).

8. Javier Etchemendi, "Un lugar en donde el agua no toca la tierra", prólogo a Severo, Noite nu norte $=$ Noche en el norte.

9. “Todos nosotros somos de la frontera" (180).

\section{AUTORES}

\section{GUIDO HERZOVICH}

Columbia University 